\title{
Ensino de Psicologia na formação de professores: uma aproximação com diálogos possíveis
}

\section{Teaching of psychology in teacher education: an approach to possible dialogues.}

*Residente em Saúde da Família e Comunidade. Grupo Hospitalar Conceição (GHC), Porto Alegre, RS, Brasil. cassioandrademachado@gmail.com

**Universidade Federal do Rio Grande do Sul - UFRGS, Docente da Faculdade de Educação e PósGraduação em Psicologia Social e Institucional, Farroupilha, Porto Alegre, RS, Brasil.

bedin.costa@gmail.com

\begin{abstract}
Resumo
Diante da dimensão de cada ciência, se faz necessário elaborar propostas curriculares para o direcionamento do ensino desses campos científicos. Quais seleções foram realizadas para pensar a colaboração da psicologia na formação de professores? Com essa inquietação como norte, elaborou-se um estudo descritivo sobre as disciplinas de Psicologia na Faculdade de Educação da Universidade Federal do Rio Grande do Sul, por meio das ementas fornecidas pela secretaria da Faculdade. A análise dos documentos revelou a clara falta de sistematização, e a semelhança entre as formações em diferentes Licenciaturas foi apenas uma das questões abordadas na discussão do trabalho, que buscou tensionar as relações entre Psicologia e Educação, que, embora apresentem interesses mútuos, no diálogo institucional, parecem não se encontrar.

Palavras-chave: Psicologia, educação, professores.
\end{abstract}




\title{
pro.posições
}

\begin{abstract}
Due to the scope of each science, it is necessary to develop curriculum proposals for the direction of teaching these scientific fields. Which selections were made to make possible the use of Psychology in teacher training? Based on an exploratory study on the Psychology courses offered as part of the curriculum in the Faculty of Education of the Federal University of Rio Grande do Sul through the syllabus provided by the secretariat of the School. The documents show a clear lack of systematization and or even similarity between the curriculum of different degrees. Finally, the study seems to support the idea that the relations between Psychology and Education in this curriculum, although based on similar interests, do not seem to engage in an institutional dialogue.

Keywords: Psychology, education, teachers.
\end{abstract}

\section{Introdução}

Regulamentada há mais de 50 anos, a formação em Psicologia hegemonicamente adotou o bacharelado como seu título a priori, característica evidenciada pela exclusividade do título de psicólogo, conferido apenas aos formandos dessa categoria; aos demais, é atribuído o título de licenciado em Psicologia, que pode ser obtido apenas de forma secundária, ou seja, após o título de bacharel. Diferentemente de outras formações, como Biologia, Matemática ou Química, as quais tiveram suas licenciaturas constituídas historicamente a partir de demandas escolares, a Psicologia se vê diante de trilhas incertas. A figura do professor de Psicologia no Ensino Médio ainda é turva. Embora a Lei de Diretrizes e Bases da Educação Nacional LDBEN (Lei BR n 9.394, 1996) aponte que o objetivo da educação básica é "desenvolver o educando, assegurar-lhe a formação comum indispensável para o exercício da cidadania e fornecer-lhe meios para progredir no trabalho e em estudos posteriores", movimentos políticos posteriores entram em contrassenso, ao retirar das diretrizes curriculares a Psicologia e a Sociologia (Klinko \& Sekkel, 2010). Além dessa dificuldade para a aproximação da licenciatura como área de atuação, comumente ela não é encontrada nas faculdades de Psicologia. Característica que, por meio de regulamentações da Associação Brasileira de 


\section{pro.posıções}

Ensino em Psicologia (ABEP), vem se alterando desde 2007. Até então, raro era o professor de Psicologia do Ensino Médio, Técnico, Superior ou de espaços informais de ensino que contasse com a Licenciatura em seu currículo.

Embora a Licenciatura em Psicologia (LP) titule o psicólogo para atuar apenas no Ensino Médio e Técnico, torna-se difícil não adotar uma postura crítica em relação ao Ensino de Psicologia (EP) em todas as áreas de conhecimento, sobretudo nos cursos voltados à formação de professores. Tal crítica inclui o EP em sua forma e conteúdo, ou seja, envolve o que será abordado da Psicologia e como os temas serão trabalhados. Essa aproximação também reflete em um estreitamento dos laços entre Psicologia e educação, e, consequentemente, com as demais licenciaturas.

Com esse novo vínculo, podemos observar o EP para/na formação de professores. Para Levandovski (2008), a aplicabilidade dos conteúdos da Psicologia à prática docente é explícita, porém a Psicologia ainda não constitui uma base teórica padrão para a melhoria da educação e do ensino. Há, em contrapartida, uma vinculação de conhecimentos psicológicos que constituem duas vertentes iniciais. A primeira, reducionista, que busca psicologizar o processo educacional, e outra que, ao reconhecer a diversidade, procura colaborar com o entendimento e a interpretação da fenomenologia educacional.

Tal discussão, consequentemente, leva-nos a diferentes e complementares questionamentos: como é apresentada a Psicologia na formação de professores? Que conteúdos/temáticas são abordados na formação universitária? Que diagrama poderíamos pensar a partir de um campo intitulado Psicologia da Educação? Qual sua articulação, em termos curriculares, entre os diferentes cursos de licenciatura? Para dar conta de tais questões, assumiremos como campo problemático o EP presente na Faculdade de Educação da Universidade Federal do Rio Grande do Sul, a partir das disciplinas obrigatórias de Psicologia ministradas a licenciandos de Letras, Matemática, Ciências Biológicas, Química, Física, Geografia e História. Para melhor sistematizar nossa observação acerca do EP na formação de professores, este trabalho será subdivido em quatro momentos:

- Panorama sobre o Ensino de Psicologia.

- As licenciaturas e a Universidade Federal do Rio Grande do Sul.

- Os currículos de Psicologia na Formação de Professores.

- Considerações acerca do Ensino de Psicologia na Formação de Professores. 


\section{pro.posições}

\section{Panorama sobre o Ensino de Psicologia}

Segundo Barros (2007), as primeiras relações entre Psicologia e educação tiveram início no desenvolvimento da Psicologia aplicada, com Alfred Binet (1857-1911), Edward B. Titchener (1867-1927), James M. Cattell (1860-1944) e Wilhem Wundt (1832-1920). No Brasil, a relação ocorreu de forma inversa: o movimento de industrialização no País na década de 1950, refletindo no crescimento populacional nas zonas urbanas, fez com que a educação se reorganizasse em razão do grande aumento de demanda. Nesse processo, a Psicologia foi utilizada de duas formas distintas e simultâneas: na primeira, os conteúdos ou conhecimentos da ciência psicológica eram lecionados primeiramente por advogados e depois por médicos e pedagogos; uma segunda forma era a utilização de teorias e técnicas, já produzidas em outros países, na organização da escola brasileira, fazendo surgir, assim, os primeiros laboratórios de Psicologia dentro das próprias escolas. Traçou-se, então, um cenário para que a Psicologia passasse a fazer parte do cotidiano escolar e, consequentemente, da formação de professores.

Desde 1987, o EP nas licenciaturas tem sido questionado. Montenegro (1987), apontado por Larocca (2000) como uma das primeiras publicações sobre a temática, descreve que uma das principais preocupações dos docentes era a seleção de conteúdo, considerando a dificuldade de selecioná-lo diante da diversidade constitutiva do conhecimento psicológico. $\mathrm{Na}$ ocasião, o autor concluiu que a importância está na apresentação da diversidade teórica, em uma perspectiva que apresente a forma como determinado conhecimento foi elaborado e sua inter-relação com outras teorias.

Já no início da década de 1990, Caparroz (1992) apontava o distanciamento do EP das práticas dos futuros professores, revelando um EP voltado às próprias teorias psicológicas. Larocca (2000) descreve mais cinco trabalhos que apresentam a dissonância entre EP nas licenciaturas e as práticas concretas vivenciadas pelos graduandos: Gatti, 1995; Guerra, 2000; Ióris, 1993; Mercuri, Batista \& Soares, 1999.

Para Guerra (2000), seria viável uma melhora qualitativa na formação de professores e no EP, mesmo nas estruturas rígidas de ensino. Para isso, mostrar-se-ia necessário, além de buscar articulações com as demais disciplinas, considerando as características de cada curso, valorizar o desenvolvimento do discente, pessoal e profissionalmente. Corroborando esse pensamento, Mrech (2007) descreve que, a partir do ano 2000, a formação de professores voltou-se para uma ênfase reflexiva: o professor passa de uma postura de professor- 


\section{pro.posições}

pesquisador, característica da década de 1990, para uma postura de professor-reflexivo, que repensa sua própria atuação em sala de aula. Para a autora, a práxis da docência de Psicologia requer, fundamentalmente, diálogo constante entre educador e educando.

Embora autores como Bock (2005) e Larocca (2007) descrevam que o EP apresenta caracteres tecnicistas, escritos de Almeida (2005) corroboram as afirmações de outros autores (Caparroz, 1992; Goulart, 1985; Ióris, 1993; Montenegro 1987), quando descreve que o maior desafio do EP se centra na descontextualização, ou seja, os estudos que verificam o caráter teórico ou técnico excessivo ou a ausência de uma postura reflexiva pouco relevam a demanda dos alunos, docentes em formação. Assim mantém-se o paradigma teoricista: estuda-se, pesquisa-se e escreve-se como o EP é feito e conclui-se o que pode ser melhorado, pouco considerando a necessidade e a demanda real do local onde o EP é realizado. Retorna-se, então, para os mesmos apontamentos dos autores acima: o EP, muitas vezes, acaba por ser abstrato, fragmentado e superficial. Ressaltamos também que essa percepção acerca do locus da Psicologia na educação, por parte do movimento crítico, já circundava o meio desde os anos 1970 (Vieira, 2008). Larocca (2007) ainda conclui que a persistência dos problemas do EP não se encerra em si, mas também deriva - e associa-se a ela - na práxis das próprias licenciaturas, caracterizada por uma herança positivista, em que há uma dicotomia entre teoria e prática.

\section{As licenciaturas e a Universidade Federal do Rio Grande do Sul}

De acordo com o Censo da Educação Superior (Instituto Nacional de Estudos e Pesquisas Educacionais Anísio Teixeira - INEP, 2009), houve um aumento de 26\% no número de alunos concluintes de cursos de licenciatura entre 2001 e 2009. Segundo Costa e Nicolay (2013), embora a discussão sobre a formação de professores para educação básica seja alvo de diversas conjeturas, foi a partir da Lei de Diretrizes e Bases do Ensino Nacional LDBEN 9.394/96 -, mais especificamente com a elaboração do primeiro plano plurianual (2000/2010), que foi possível estabelecer um campo efetivo para a investigação e a proposição 


\section{pro.posições}

acerca do ensino universitário. O Decreto n³.276, de 6 de dezembro de 1999, aponta que, entre outras, as seguintes competências devem ser desenvolvidas:

I - comprometimento com os valores estéticos, políticos e éticos inspiradores da sociedade democrática; II - compreensão do papel social da escola; III - domínio dos conteúdos a serem socializados, de seus significados em diferentes contextos e de sua articulação interdisciplinar; IV - domínio do conhecimento pedagógico, incluindo as novas linguagens e tecnologias, considerando os âmbitos do ensino e da gestão, de forma a promover a efetiva aprendizagem dos alunos; V - conhecimento de processos de investigação que possibilitem o aperfeiçoamento da prática pedagógica; VI - gerenciamento do próprio desenvolvimento profissional. (Art. $5^{\circ}$, par. $1^{\circ}$ )

Dessa forma, o decreto expõe o imperativo de uma formação complexa e transversal, que objetive a integralidade do sujeito educador.

Atualmente, a Universidade Federal do Rio Grande do Sul conta com 17 cursos de licenciatura, com disciplinas específicas, comumente ministradas em suas respectivas faculdades, e disciplinas comuns ofertadas na Faculdade de Educação, nas quais a convergência de diversas licenciaturas une alunos de diferentes cursos. O Departamento de Estudos Básicos - DEBAS - é um dos responsáveis pela organização e pelo ensino de disciplinas partilhadas conjuntamente pelos cursos de licenciaturas da universidade. $O$ Departamento é constituído por cerca de 30 professores de 4 áreas: Filosofia da Educação, História da Educação, Psicologia da Educação e Sociologia da Educação.

\section{Os currículos de Psicologia na Formação de Professores}

Serão apresentadas as disciplinas de Psicologia que são ofertadas de forma obrigatória para os cursos de Licenciatura em Letras, Matemática, Ciências Biológicas, Química, Física, Geografia e História no $1^{\circ}$ semestre de 2013. No entanto, faz-se importante destacar que, além das disciplinas obrigatórias, a Psicologia se faz presente de forma eletiva em outras tantas, essas não incluídas no estudo em questão. Os currículos das licenciaturas selecionadas foram acessados no website da Universidade, e as ementas das disciplinas solicitadas ao Departamento de Ensino Básico, setor responsável para a realização desse requerimento na 


\section{pro.posições}

Faculdade de Educação da UFRGS. Verificamos a necessidade de um estudo exploratório para subsidiar o avanço de discussões acerca do Ensino de Psicologia pelo corpo docente e discente.

\section{Disciplinas}

Foram identificadas quatro disciplinas de Psicologia ofertadas: Psicologia da Educação I, Psicologia da Educação II, Psicologia da Educação: A educação e suas instituições e Psicologia da Educação: A adolescência. Tal distribuição pode ser visualizada no Quadro 1.

Quadro 1: Disciplinas de Psicologia ofertadas para as licenciaturas na Faculdade de Educação da Universidade Federal do Rio Grande do Sul

\begin{tabular}{|c|c|c|c|}
\hline Curso & Disciplina & Créditos & Semestre \\
\hline Letras & Psicologia da Educação I & 2 & $3^{\circ}$ \\
\hline Matemática & $\begin{array}{l}\text { Psicologia da Educação I } \\
\text { Psicologia da Educação II }\end{array}$ & $\begin{array}{l}2 \\
2\end{array}$ & $\begin{array}{l}1^{\circ} \\
2^{\circ}\end{array}$ \\
\hline $\begin{array}{l}\text { Ciências } \\
\text { Biológicas }\end{array}$ & $\begin{array}{l}\text { Psicologia da Educação I } \\
\text { Psicologia da Educação II }\end{array}$ & $\begin{array}{l}2 \\
2\end{array}$ & $\begin{array}{l}4^{\circ} \\
5^{\circ}\end{array}$ \\
\hline Química & Psicologia da Educação I & 2 & $3^{\circ}$ \\
\hline Física & $\begin{array}{l}\text { Psicologia da Educação: A educação e suas } \\
\text { instituições } \\
\text { Psicologia da Educação: A adolescência }\end{array}$ & 2 & $1^{\circ}$ \\
\hline Geografia & $\begin{array}{l}\text { Psicologia da Educação I } \\
\text { Psicologia da Educação II }\end{array}$ & $\begin{array}{l}2 \\
2\end{array}$ & $\begin{array}{l}2^{\circ} \\
3^{\circ}\end{array}$ \\
\hline História* & - & - & - \\
\hline
\end{tabular}

*A Licenciatura em História não oferta, de forma obrigatória, disciplinas de Psicologia no seu currículo.

Fonte: Elaborado pelos autores 


\section{pro.p̣osıções}

\section{Ementas}

Segue a descrição integral das ementas das disciplinas identificadas:

Psicologia da Educação I: Introdução ao estudo da(s) psicologia(s) e seu interesse para o campo da educação. A constituição do sujeito (desenvolvimento/aprendizagem) na sua relação com os outros no âmbito da cultura. Estudo das relações entre professores e alunos.

Psicologia da Educação II: Estudo das teorias psicológicas que abordam a construção do conhecimento, destacando as teorias interacionistas e suas contribuições para a pesquisa e as práticas educativas.

Psicologia da Educação: A Educação e as Instituições: Análise do status do ensino e da aprendizagem em Instituições Educativas e as modalidades de intervenção utilizadas, bem como as relações internas e externas estabelecidas (grupos de trabalho, serviços, sociedade civil) e sua repercussão no ensino e na aprendizagem. Medidas institucionais para a qualificação do ensino e da aprendizagem. Funcionamento institucional: análise e intervenção. Grupos: funcionamento, tipos, abordagem na escola. Educação e Poder.

Psicologia da Educação: A Adolescência: Estudo da adolescência do ponto de vista dos aspectos psicológicos (cognitivos, psicossexuais e psicossociais), pedagógicos (situação de ensino-aprendizagem) e biológicos (crescimento físico e puberdade), com destaque para a análise da realidade brasileira. Cultura e adolescência. Adolescência e escola.

\section{Programas}

Para complementar a pesquisa foram solicitados ao DEBAS os programas das disciplinas estudadas. Para melhor visualizá-las, foram dispostas na Tabela 1. 


\section{pro.posıções}

Tabela 1: Programas das disciplinas de Psicologia ofertadas para as licenciaturas na Faculdade de Educação da Universidade Federal do Rio Grande do Sul

\begin{tabular}{|c|c|}
\hline Disciplinas & Descrição \\
\hline \multicolumn{2}{|l|}{ Psicologia da Educação I } \\
\hline - Teorias Psicológicas & $\begin{array}{l}\text { Principais teorias e suas contribuições para a educação e a } \\
\text { aprendizagem }\end{array}$ \\
\hline - Subjetividade & Constituição da subjetividade ao longo do ciclo vital \\
\hline - As relações professor-aluno & $\begin{array}{l}\text { Relações professor-aluno, o desejo de saber, o ensino e a } \\
\text { aprendizagem. }\end{array}$ \\
\hline - Temas contemporâneos & $\begin{array}{l}\text { Problematização de temas contemporâneos em Psicologia e } \\
\text { Educação }\end{array}$ \\
\hline \multicolumn{2}{|l|}{ Psicologia da Educação II } \\
\hline - Piaget e Vygotsky (P\&W) & $\begin{array}{l}\text { Problemas e contribuições para a Psicologia cognitiva e para a } \\
\text { educação }\end{array}$ \\
\hline - Desenvolvimento em (P\&W) & $\begin{array}{l}\text { Fatores relacionados com a cognição, da infância à idade } \\
\text { adulta }\end{array}$ \\
\hline - Estágios de desenvolvimento & $\begin{array}{l}\text { Psicogênese da inteligência, cultura, procedimentos de } \\
\text { investigação. }\end{array}$ \\
\hline $\begin{array}{l}\text { - Processos cognitivos em } \\
(\mathrm{P \& W})\end{array}$ & $\begin{array}{l}\text { Piaget: os processos de adaptação e Vygotsky; a mediação } \\
\text { simbólica. }\end{array}$ \\
\hline \multicolumn{2}{|c|}{ Psicologia da Educação: A Educação e as Instituições } \\
\hline - Psicologia Institucional & $\begin{array}{l}\text { Análise do status do ensino e da aprendizagem em Instituições } \\
\text { Educativas }\end{array}$ \\
\hline - Processos de grupo & $\begin{array}{l}\text { Modalidades de intervenção, relações estabelecidas e sua } \\
\text { repercussão }\end{array}$ \\
\hline - Relações entre saber e poder & $\begin{array}{l}\text { Medidas institucionais para a qualificação do ensino e da } \\
\text { aprendizagem }\end{array}$ \\
\hline - Instituições sociais & Funcionamento institucional: análise e intervenção. \\
\hline \multicolumn{2}{|c|}{ Psicologia da Educação:A Adolescência } \\
\hline - Juventude e puberdade & Problematização de questões relativas a puberdade \\
\hline - Como construção social & Problematização da construção social atual do adolescente \\
\hline - Temas atuais & Estudo de alguns fenômenos da adolescência atual \\
\hline - Transformações & Discussão teórica baseada no autor Humberto Maturana \\
\hline
\end{tabular}

Fonte: Elaborado pelos autores 


\section{pro.posições}

\section{Considerações acerca do Ensino de Psicologia na Formação de Professores}

Em primeira análise percebemos a falta de homogeneidade entre as disciplinas propostas nos diferentes cursos de licenciatura, como: o curso de História não possui disciplinas de Psicologia obrigatórias em seu currículo; o curso de Física não apresenta disciplina de Psicologia introdutória; o curso de Matemática oferta a disciplina em seu primeiro e segundo semestres; já o curso de Ciências Biológicas, no quarto e no quinto semestres; os cursos de Letras e Química possuem dois créditos de disciplinas de Psicologia e os demais possuem quatro, com exceção do curso de História. A disparidade quanto à disposição das disciplinas de Psicologia, embora evidente, não possibilita inferência causal. Porém algumas relações podem ser efetuadas. Segundo Almeida (2005), o EP pode ser caracterizado por sua descontextualização, o que pode torná-lo dispensável e/ou até mesmo improdutivo para licenciaturas. Assim, verificamos a necessidade de melhor organização curricular por parte do corpo docente, o que pode resultar na presença mais intensa da Psicologia no currículo, uma vez que, teoricamente, a sua relevância para a educação é evidente.

A apresentação do programa vem contribuir com a compreensão das ementas. Assim, Psicologia da Educação I aborda as teorias psicológicas de forma generalista, o que contribui com seu caráter introdutório, já a Psicologia da Educação II apresenta para o aluno questões referentes às teorias de Piaget e Vygostky, suas contribuições e limitações para a educação. Psicologia da Educação: A Educação e as Instituições permite compreender que a disciplina aborda questões referentes a processos grupais e institucionais, e reforça a importância de uma disciplina destinada para sua introdução como a Psicologia da Educação I. E Psicologia da Educação: A Adolescência expõe questões pertinentes a juventude e puberdade, com ênfase em temáticas contemporâneas.

Quanto às ementas, considerando-as como resumo da proposta de trabalho da disciplina, e nunca como uma descrição completa, é razoável elaborar um panorama em que Psicologia da Educação I apresenta uma introdução às teorias psicológicas e Psicologia da Educação II discorre sobre as contribuições dessas teorias para a educação. Psicologia da Educação: $A$ Educação e as Instituições e Psicologia da Educação: A Adolescência são disciplinas intermediárias, que abordam temáticas específicas, o que poderia dificultar tanto a adesão dos alunos à disciplina 


\section{pro.posıções}

quanto o manejo do professor em aula. Além disso, são disciplinas que não requerem liberadores, ou seja, não exigem que o aluno curse obrigatoriamente outra disciplina para viabilizar a matrícula, o que, ao considerar a ementa da Psicologia da Educação I, poder-se-ia considerar propício. Larocca (2007) defende que o Ensino de Psicologia, tanto no âmbito da saúde quanto na educação, utiliza-se de parâmetros tecnicistas em demasia, a despeito dos projetos pedagógicos dos cursos superiores atuais. Utilizando-se dos pressupostos de Giroux (1986), a autora defende uma postura emancipatória por parte do docente, o que, pelos documentos utilizados, não é possível verificar com nitidez. Para essa verificação, mostrar-seia necessária a descrição da metodologia utilizada em aula ou depoimentos dos docentes responsáveis pelas disciplinas e dos respectivos discentes.

Embora Larocca (2007) refira a necessidade de contrapor à perspectiva técnica uma perspectiva reflexiva, que considere o professor não como técnico, mas como "intelectual transformador", somada à descrição de Almeida (2005) de um EP descontextualizado, pode-se inferir que, como a maioria das dicotomias, ambas representam perspectivas simplistas da situação. A contextualização poderia estar na proposição dos diferentes prismas da Psicologia: tecnicista, reflexiva e emancipadora. Assim não há escolha por parte do docente ou do pesquisador e, se aplicada a outra população ou outra turma de discentes, comumente haverá de ser descontextualizada. Conferir importância aos diferentes prismas da Psicologia delega ao discente, durante sua prática, utilizar-se do arcabouço que lhe propôs maior identificação.

Reconsiderando a formação docente como um complexo conjunto de experiências, Boterf (2003) agrega a ideia de que, para desenvolver competências profissionais, é necessária uma instrumentalização de saberes e capacidades, mas não apenas. $\mathrm{O}$ autor ainda afirma que há os saberes que se mobilizam apenas em determinados contextos, que podem ser conceituados como "o saber agir em situação", e, portanto, a competência se dá também na administração dessas situações, o que, consequentemente, impossibilitaria sua avaliação e estudo não regionalizado no locus de atuação. Assim, aferições do impacto e da reverberação acerca do ensino de Psicologia não se fazem por meio de estudos de delineamento caracteristicamente documental, mas preferencialmente em contato com os sujeitos. Porém, estudos exploratórios como o apresentado neste artigo são importantes subsídios para a continuidade da temática acerca da proposta. Sugerimos, para a aquisição de resultados mais sólidos em investigações futuras, o contato direto com os atuais discentes das diferentes 


\section{pro-posıções}

licenciaturas, com os docentes de Psicologia e com os demais profissionais de educação em atuação.

Descrever conteúdos e/ou competências favoráveis à prática docente, por si, compreende uma tarefa deveras grandiosa para esse trabalho. Muito provavelmente inalcançável, se não com o esforço conjunto de docentes, discentes e acadêmicos. Nesse sentido, consideramos insubstituível o contato com os docentes e os discentes para uma melhor análise crítica acerca da EP na formação de professores. Jamais foi pretensão deste estudo realizar apontamentos à organização institucional, mas realizar um trabalho descritivo que subsidie espaços de crítica e reflexão acerca do posicionamento da Psicologia na formação docente.

\section{Referências Bibliográficas}

Almeida, P. C. A. de. (2005). Os saberes necessários à docência no contexto das reformas para a formação de professores: o caso da psicologia da educação (253 pp.). Tese de Doutorado em Educação, Faculdade de Educação, Universidade Estadual de Campinas, Campinas, SP.

Barros, C. C. (2007). Reflexão sobre a formação de professores de Psicologia. Temas em Psicologia, 15 (1), 33-39.

Bock, A. M. B. (2005). Um novo projeto para a profissão no Brasil: o compromisso social da Psicologia. In 5 Encontro Nacional da Associação Brasileira de Estudos Populacionais - ABEP. São Paulo: Pontifícia Universidade Católica de São Paulo.

Boterf, G. Le (2003). Desenvolvendo a competência dos profissionais (3a ed., 237pp.). Porto Alegre: Artmed.

Caparroz, A. de A. (1992). A psicologia na educação e os cursos de licenciatura nas faculdades particulares do município de São Paulo (203 pp.) Dissertação de Mestrado em Educação, Pontifícia Universidade Católica de São Paulo, São Paulo.

Costa, L. B. da, \& Nicolay, D. A. (2013). Na zona curricular: o problema da simetria invertida no ensino-aprendizado nas licenciaturas. In D. A. Nicolay, \& A. P. Gravina, O currículo em suas interfaces com a educação básica e superior (pp. 142-165). Curitiba: Editora CRV. 


\section{pro-posıções}

Guerra, C. T. (2000). Conhecimentos psicológicos e formação de professores. In R. G. Azzi, S. H. de S. B. Batista, \& A. M. de A. Sadalla, Formação de professores: discutindo o ensino de psicologia (pp.180-202) Campinas: Alínea.

Instituto Nacional de Estudos e Pesquisas Educacionais Anísio Teixeira - INEP. (2009). Resumo técnico: Censo da Educação Superior de 2009. Brasília: Ministério da Educação MEC. Retirado em 28de novembro de 2013, de <http://download.inep.gov.br/download/superior/censo/2009/resumo_tecnico2009 $. p d f>$

Klinko, J., \& Sekkel, M. C. (2010). Psicologia no ensino médio: sobre os desafios de ser professor. Psicologia, Ensino \& Formação, 1 (2), 73-83.

Larocca, P. (2000). O saber psicológico e a docência: reflexões sobre o ensino de psicologia na educação. Psicologia, Ciência e Profissão, 20 (5), 60-65.

Larocca, P. (2007). O ensino de psicologia no espaço das licenciaturas. Educação Temática Digital, 8 (2), 295-306.

Levandovski, A. R. (2008). Contribuição da disciplina Psicologia da Educação para a prática docente no Ensino Fundamental I - um estudo por meio da Metodologia da Problematização (230 pp.). Dissertação de Mestrado em Educação, Universidade Estadual de Londrina, Londrina, PR.

Montenegro, M. E. (1987). A psicologia educacional nas licenciaturas no estado de Goiás (354 pp.). Dissertação de Mestrado em Educação, Faculdade de Educação, Universidade Estadual de Campinas, Campinas.

Mrech, L. M. (2007). Um breve histórico a respeito do ensino de psicologia no ensino médio. Educação Temática Digital, 8 (2), 225-235.

Vieira, R. de C. (2008, dezembro). O psicólogo e o seu fazer na educação: uma crítica que já não é mais bem-vinda. Psicologia da Educação, 27, 179-192. Retirado em 10 de janeiro de 2015, de <http://pepsic.bvsalud.org/scielo.php?script=sci_arttext\&pid=S1414-

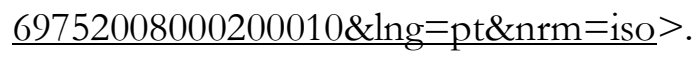

\section{Legislação}




\section{pro.posıções}

Lei BR $n^{\circ}$ 9.394, de 20 de dezembro de 1996. (1996). Presidência da República, Casa Civil. Retirado em 26 de dezembro de 2013, de <http://www.planalto.gov.br/ccivil_03/leis/19394.htm>

Lei BR $n^{\circ}$ 3.276, de 6 de dezembro de 1999. (1999). Presidência da República, Casa Civil. Retirado em 26 de dezembro de 2013, de <http://www.planalto.gov.br/ccivil_03/decreto/D3276.htm>

Submetido à avaliação em 27 de junho de 2014; aprovado para publicação em 22 de setembro de 2015. 